\title{
Psychotherapy trainees' epistemological assumptions influencing research-practice integration
}

\author{
Attà Negri, ${ }^{1}$ Giovanbattista Andreoli, ${ }^{1}$ Luca Belotti, ${ }^{1}$ Arianna Barazzetti, ${ }^{1}$ E. Hale Martin ${ }^{2}$ \\ ${ }^{1}$ Department of Human and Social Sciences, University of Bergamo, Bergamo, Italy; ${ }^{2}$ Graduate School of Professional Psychology, \\ University of Denver, Colorado, USA
}

\begin{abstract}
Over the last few decades a growing number of psychotherapy scholars as well as psychotherapy researchers have joined a paradigm shift, moving from a reductionist to a complexity-oriented epistemology. Many authors recognize that when human subjectivity is the object of intervention and study, it is appropriate to resist simplification and to assume a more complex approach. While this paradigm shift is taking place not only in psychology but also in other disciplines, many psychotherapists still share the assumption that psychotherapy practice and psychotherapy research have opposite values; hence, they are worlds that cannot be reconciled. Considering this as one of the main reasons preventing a useful integration of evidence-based practice and clinical training in psychotherapy, we conducted an online survey of 126 Italian trainees from three differently-oriented psychotherapy institutes (cognitive-behavioral, relational-psychoanalytic and relational-systemic) to explore the epistemology underling the clinical and research practices. After presenting a clinical vignette, we asked questions about diagnostic considerations, case formulations, and treatment plans; we also asked questions about participants' involvement in research projects or in research methodology courses and about willingness to be involved in future research studies in their clinical practice. We found some significant differences among trainees with different orientations, but in general most of the responses reflected a positivistic epistemology underlying both clinical and research activities. These findings suggest that a deeper awareness of one's own epistemological assumptions could help trainees foster a more theory-coherent and research-informed clinical practice.
\end{abstract}

Key words: Psychotherapy training; Research epistemology; Psychotherapy epistemology; Evidence-based psychotherapy; Researchpractice gap.

Correspondence: Attà Negri, Department of Human and Social Sciences, University of Bergamo, Piazzale S. Agostino 2, 24129 Bergamo, Italy.

Tel. +39.035.2052914.

E-mail: atta.negri@unibg.it

Citation: Negri, A., Andreoli, G., Belotti, L., Barazzetti, A., \& Martin, H. (2019). Psychotherapy trainees' epistemological assumptions influencing research-practice integration. Research in Psychotherapy: Psychopathology, Process and Outcome, 22(3), 344-358. doi: 10.4081/ripppo.2019.397

Contributions: AN contributed to all the phases of the study; GA participated in research design development, data collection, coding, and writing the article; LB participated in data collection, coding, statistical analysis and writing the article; $\mathrm{AB}$ contributed to data collection and writing the article; HM took part in research design development, results interpretation and in writing the article.

Conflict of interest: the authors declare no potential conflict of interest.

Received for publication: 31 March 2019.

Revision received: 28 October 2019

Accepted for publication: 2 November 2019

This work is licensed under a Creative Commons Attribution NonCommercial 4.0 License (CC BY-NC 4.0).

${ }^{\circ}$ Copyright: the Author(s), 2019

Licensee PAGEPress, Italy

Research in Psychotherapy:

Psychopathology, Process and Outcome 2019; 22:344-358

doi:10.4081/ripppo.2019.397

\section{Introduction}

A significant divide between scientific research and clinicians practice in psychology has been highlighted by many authors and institutions (e.g., APA Presidential Task Force, 2006; Barlow, 1981; Castonguay \& Muran, 2015; Cohen, Sargent, \& Sechrest, 1986; Kazdin, 2016; Melidonis, 1989; Morrow-Bradley \& Elliott, 1986; Westen, 2007). Many clinicians are reluctant to introduce research findings into their practice, and researchers rarely plan research designs inspired and informed by daily clinicians practice. This gap is particularly evident in the field of psychotherapy where psychotherapeutic practice and psychotherapy research seem to be two distant and different worlds (Boisvert \& Faust, 2006; Wilson, Armoutliev, Yakunina, \& Werth, 2009). Several explanations for this persistent phenomenon have been proposed, as well as consequent solutions to close this gap (Beutler, Williams, Wakefield, \& Entwistle, 1995; Drapeau \& Hunsley, 2014; Fitzpatrick, 2012; Lilienfeld, Ritschel, Lynn, Cautin, \& Latzman, 2013;). For example, Tasca, Grenon, FortinLangelier and Chyurlia (2014) summarized three main difficulties in integrating psychotherapy research findings and clinical practice: i) clinicians consider research results as not always relevant to real-world practice; ii) both academic researchers and clinical communities contribute to shortcomings in communication and connection; iii) 
psychotherapy practice itself is fragmented in terms of clinicians training, settings involved, and range of clients' problems as well other divisions. Many solutions have been proposed, including invitations to create collaborative researcher-clinician communities (Tasca et al., 2014; Westen 2007), conducting practice-based research focused on clinical practice in real-world contexts (e.g., Crooke \& Olswang, 2015; Liddle, 1991), promoting conditions to expose more clinicians to research findings (Gallo \& Barlow, 2012; Lilienfeld et al., 2013), and teaching specific courses on evidence-based practice to bachelor's and master's students (Bearman, Wadkins, Bailin, \& Doctoroff, 2015; Goldfried, 1984).

Although these explanations and solutions for the research-practice gap in psychotherapy could be useful, there are authors (e.g., Fourie, 1996; Hoshmand \& Polkinghorne, 1992) who assume a more critical and central explanation why this gap continues despite efforts to close it. They highlight the difficulty researchers, clinicians, trainers and students have in adopting an epistemological position that is consistent with the characteristics of psychotherapeutic action. In other words, what divides research from practice in the field of psychotherapy is the assumption of a positivistic concept of science, knowledge and intervention, which is not reflective of the highly complex reality of human beings.

The purpose of this work is to understand why this incongruity is problematic for both research and practice. Moreover, we investigate how the assumptions of a constructionist epistemology, which Ceruti (1996) defined as an epistemology of complexity, might reduce the gap between research and practice and make both research and psychotherapeutic practice more useful. We will highlight this perspective starting with the results of a survey administered to 126 trainees from three Italian psychotherapy training institutes with differing clinical orientations and epistemological positions. We think that investigating the epistemological assumptions of trainees in psychotherapy is relevant and useful as they reflect contemporary dominant professional culture, so they can better highlight the constraints and possibilities of the current way of thinking.

\section{Positivistic and complexity epistemology}

The positivistic epistemology assumes that reality exists out there, independent of the observer (Guba \& Lincoln, 1988), and that truth is directly and objectively discoverable by applying the methods of science (Casti, 1989). It is a realist and empiricist approach which presupposes a correspondence between scientific knowledge and external reality that is explainable in operating laws thanks to empirical verification. Scientific knowledge, thus, proceeds by accumulation of new discoveries added to the previous ones. Scientific knowledge ideally should move toward omniscience, assuming a perfect knowledge of reality is possible. The final goal of this perspective is to reach the application of objective knowledge to allow humanity to prevent and control wide sectors of reality. This would be possible by boiling the complexity of events down to valid laws, which are discoverable and reproducible by the scientific community. Following this path, the world becomes easy, rational and causal (Ceruti, 2015).

In this epistemological framework, scientific knowledge is advanced by the empirical methods of research, by which hypotheses are tested in replicable experimental designs. In this way, simple cause-and-effect relationships are elucidated because the contribution of each part is additive, such that the whole is exactly the sum of the parts. We could underline that the implicit premises of empirical research methods consist of stable and predictable results, outputs proportional and correspondent to inputs, and linear conceptions of space, time and cause-and-effect relationships.

In this method the researcher is considered capable of observing and studying their object of investigation in an impartial and conceptual manner. The researcher can subdivide the reality in a way that makes their able to isolate the variables and isolate the object of study from perturbations. It is thus possible to know and observe the phenomenon as it actually is. The consequence is that the subjectivity of the researcher and the context in which the research takes place can be removed from the analysis (Bertin, 2013; Butz, 1997). This approach aims to discriminate what is permanent from what is temporary and what is essential from what is unnecessary. Only the disciplines that use this method can be accepted as providing valid knowledge. To apply these principles, the laboratory becomes the setting where knowledge can be revealed because it: i) purifies the object of study from every external disturbance; ii) isolates the variables involved in the study; iii) creates special experimental conditions that are completely controllable and replicable; iv) goes beyond researchers' subjectivity and the situations in which the experiment is conducted.

In the twentieth century dominated by this logical positivism, the possibility of adopting a different epistemology, especially for intangible and difficult to measurable objects of study such as psychological ones, gradually made its way into the scientific community (Bateson, 1972, 1979; Capra, 1983; Engel, 1992; Kenny, 1989). Many authors refer to this second epistemology as constructionism (Gergen, 1982) since reality does not exist independently of the observer but is always a shared construction in a given socio-cultural context. Reality exists but is knowable only through a subjective point of view. When an observation is made, what is known is not the object itself, but rather ideas about the object within the linguistic and cultural categories shared by the observer with their contexts. The knowledge of reality is therefore not a simple, linear and one-sided action but instead becomes a complex effort that implies the possibility of mul- 
tiple interpretations and points of view. In this sense we share the idea of calling this epistemological perspective an epistemology of complexity in that it recognizes the central characteristic of knowledge as complexity.

In this epistemological framework scientific knowledge proceeds by trial and error and by paradigmatic changes (Kuhn, 1962). Scientists can only make assumptions about reality that may or may not be shared intersubjectively and that can be judged plausible and useful to explain a certain experience of a certain reality, but that cannot be considered valid or true in an absolute way. Instead of the systematic control of variables and of subjectivity proposed by positivism, a complexity epistemology introduces intersubjective sharing of temporary hypotheses and the plurality of points of view on reality that bring scientists closer to its plausible, ecological, contextual and always temporary knowledge. In the epistemology of complexity, due to interdependent parts whose contribution to the whole is multiplicative, simple cause-and-effect relationships vanish. Time and space can assume a more complex representation, as for example a circular one.

Thus, the application of the positivistic research paradigm to therapy is severely limited. We cannot isolate people or relationships at any level, neither symbolically nor literally, without destroying their wholeness. For example, timing is fundamental: the same intervention that at a given moment is welcome and incisive, might be intrusive and injurious at another moment (Ford \& Urban, 1998; Varela, 1989; Young, 1995).

Within the complexity epistemology, living systems are viewed as complex, dynamic systems (Ceruti, 2018; Luhmann, 1995). In complex systems, such as couples, families, or societies, small inputs often give rise to unexpectedly wide consequences, while huge inputs sometimes have little or no effect at all. The properties of such systems are not directly deducible from the properties of their parts but can emerge unexpectedly from relationships and links between system elements (Cambel, 1993; Ceruti, 2018; Rosas, 2017). Complex systems are highly sensitive both to initial conditions and to disturbances they encounter during their development. For this reason, in psychotherapy and in social sciences in general, we do not have a continuous and predictable evolution (Butz, 1997; Dimitrov \& Woog, 2000; Miller \& Page, 2007). Furthermore, in this epistemology the observer is to be considered internal and inseparable from the observed system, so as to modify its dynamics. In this way, every observational act also becomes an act of intervention (Luhmann, 1995).

The epistemology of complexity presents researchers with complex challenges: i) accepting the possibility that what is observed or expected in a particular context can change in another context, ii) accepting the existence of a multiplicity of points of view that cannot be arranged in a hierarchy, and iii) trying to combine the multiple points of view and explanations of reality and not reducing one to the other.
The two epistemologies briefly described here are mutually exclusive: either one assumes that reality is absolute, or one assumes that it is co-constructed. However, the question is not which epistemology produces truer or more scientific results, rather both clinicians and researchers in psychotherapy have to decide which epistemology is more useful and consistent with the characteristic of their object of study and intervention. We believe that intangible objects like human beings cannot be treated and investigated as tangible objects. Subjectivity and variability are their central feature, and they exist only within the intersubjective encounter. Thus, adopting an epistemology of complexity appears more useful and consistent than a positivist epistemology when one wants to study infinitely complex phenomena. However, this does not imply that complexity is superior to positive epistemology and can replace it. Rather, traditional empirical methods are included within the complexity epistemology as one possible way to knowledge. It offers a specific discursive and intersubjective practice through which researchers can share hypotheses and potential answers within defined rules of knowledge. Furthermore, in the complexity epistemology linear cause-and-effect relationships can emerge under well-constrained conditions, as a singular emergence of a system at a certain time and state (Ackerman, Darling, Lee, Hiatt, \& Shim, 2016).

\section{Implications of epistemological approaches for psychotherapeutic and research practices}

Psychology and psychotherapy as well as social sciences in general have grappled with the dominant positivistic epistemology. Many psychological and psychotherapeutic theories are grounded explicitly or implicitly in a positivist paradigm of science and of human beings. Behaviorism for example focuses its attention on the definition of psychology as a purely objective experimental branch of natural science with its theoretical goal being the prediction and control of behavior (Watson, 1913, p. 158). Also, the Freudian metapsychology adopted, even if with many contradictions, a positivistic epistemology (Assoun, 1981; De Robertis, 2001). Freud strenuously and repeatedly considered psychoanalysis as a natural science. He considered and described the mind as an external object whose truth can be interpreted thanks to the analyst's knowledge of the drives functioning very similarly to those of chemistry and physics. Even in the systemic orientation there was an early positivist phase during which the cybernetic reading of living systems sought to reach an objective view of the functioning of observed systems (Watzlawick, Bavelas, \& Jackson, 1971).

Fortunately, over the last few decades a growing number of psychotherapy scholars as well as psychotherapy researchers have joined the paradigm shift, moving from a reductionist to a more complexity-oriented epistemology. Many authors recognize that when human subjectivity is the object of intervention and study, it is appropriate 
to resist simplification and to assume a more complex approach. Examples of this epistemological shift are seen in psychoanalysis with the emergence of intersubjective theories and the relational track, in cognitivism with the postrationalist turn, and in the systemic orientation with the transition to second order cybernetic theories.

Within this background, we can identify some common elements and conclusions shared by clinicians adopting a complexity epistemology:

- A therapist is not an external observer of the therapeutic relationship but rather contributes to co-create reality at the same level as a patient; the therapist's subjectivity is valued as an indispensable tool through which to build a useful relationship with and for the patient; in this sense the expert is both patient and therapist, and they can share hypotheses on what is happening in the therapeutic relationship and in patient's life; these hypotheses are only some among the multiple possible readings of reality generated from specific points of view;

- the mind is seen as a flexible, open and complex system: flexible and open because it is in continuous interconnection with others and with contexts; complex because to understand its functioning it is necessary to take into account multiple levels, multiple elements, multiple points of view, and multiple explanations simultaneously;

- causal and non-causal relationships between events, elements, and people are seen by the therapist as multiple and even circular; the scheme of representation and understanding of time is not only linear - past, present, future - but also overlapping and even circular; the relationship between antecedents and consequents is always multilinear and manifold;

the mind is not reified into a series of semi-concrete entities (e.g. intelligence, unconscious, personality, trauma, disorder, etc.) as if they exist like other tangible objects; rather, the therapist uses the concepts as heuristics, as temporary metaphors useful as long as they serve to give shared meaning to the experience; thus, the mind is considered a dynamic system insomuch as it is composed of processes continually changing in shifting contexts rather than a set of stable states or entities; in this sense nosographic and descriptive diagnosis is of little utility if it fragments and reifies the reality of the mind; diagnosis then is useful only to the extent that it helps give a sense - always contextual, specific and consensual - of events, behaviors, sensations, and thoughts; thus, diagnosis becomes a two-way process of finding meaning in the patient's story and in the therapeutic relationship. It is always a process of shared knowledge about a shared reality of which the therapist is a part, and it is not an impartial and neutral fact that informs the treatment, but rather the result of mutual influences that drive change in the ongoing processes;
- the aim of therapy is not to transform the patient from the current state to another one defined a priori as desirable for all patients showing similar problems, which implies that therapists have to know the technical actions or tools to bring the patient from the initial to the desired final situation; rather, therapy aims can be defined as methodological, with the primary objective of creating a working method, a relationship able to activate processes in that specific patient that can lead to changes desirable for them; the therapeutic action becomes an action on the constraints and possibilities within which a specific system moves rather than an action aimed at transforming the system itself. A complexity-oriented epistemology also has implications in doing and considering research procedures. Researchers and clinicians who adopt this epistemological orientation will no longer consider traditional research methods (laboratory experiments, randomized clinical trials, quasi experiments, etc.), based on the control of subjectivity and variability, as the only source of valid of scientific knowledge (Kiesler, 1981). These kinds of studies reflect a positivistic epistemology with research methods that are indeed anything but objective in the human sciences. Rather, they are dialogical and consensual procedures used to reach understandings that are not absolute nor truer than understandings that are derived from other research procedures grounded in other epistemologies. Thus, all results are always social constructions and do not reflect an absolute reality (Hammersley \& Atkinson, 1983).

Many other shifts occur when a complexity epistemology is applied in research. For example, Darlaston-Jones (2007) maintains that the scientific rigor typical of positivistic research methods is to be reinterpreted and broadened as systematic investigations of the roles, values, motivations, and influences of the researcher in the investigation. There is continuing skepticism of hypotheses, methods, results, and interpretations as well as an ethical orientation that considers the utility of research for society. Finally, the shift adopts a greater flexibility in methodology geared to understand and respect the unique characteristics of the individuals. Other implied shifts could include: i) from discovering the truth to making sense (Fourie, 1996): the research process does not lead to the confirmation of the true hypotheses corresponding to reality, but rather to the selection of those that in a given period and context can appear as plausible and above all useful for understanding and acting in that context; ii) from replicability that considers findings as valid or real if it can be found in more than one instance of observation to intersubjective sharing of some interpretations within specific contexts; iii) from control of subjectivity and variability to the use of subjectivity in the context as a unique tool of knowledge; iv) from reliance in the methods and scientific rigor to ongoing reflexive practices (Ryan, 2006).

The creation of new research methods, appropriate for research with humans and consistent with a complexity 
epistemology, is at its beginning. One of the main instruments that can solve the difficulty in studying human complexity and give more value to the idiographic description is the single case study (e.g., Hayes, 1981; Hoffman, 2009; Kazdin, 1981; Wall, Kwee, Hu, \& McDonald, 2017). However, other methods focused on reflexivity procedures, research-action and systematic analyses of specific contextualized situations have been proposed (Cronbach, 1975; Hoshmand \& Polkinghorne, 1992; Schön, 2017).

\section{Epistemology, research and psychotherapy training}

Many psychotherapists share the assumption that psychotherapy practice and psychotherapy research have competing values and thus are worlds that cannot be reconciled. We agree with those who believe that this is due to a lack of awareness and reflection on the epistemological assumptions on which clinical practice and research activity are based (Fourie, 1996; Hoshmand \& Polkinghorne, 1992). Our hypothesis is that in the absence of such explicit reflection both researchers and clinicians implicitly adopt the dominant epistemology in western society, namely a positivistic epistemology. In this way the gap between clinical work and research seems unbridgeable because the empiricist research methods typical of logical positivism give little relevant information to inform the complexity of clinical activity. Because of this, clinicians feel a fundamental inconsistency in applying research methods that feel implicitly incongruent with and not useful for the daily experiences of their clinical practice.

University courses in psychology as well as postgraduate training programs in psychotherapy could play an important role in either closing or maintaining the research-practice gap. Postgraduate psychotherapy training in particular, if intended to somehow integrate the world of practice and research, has to face these challenges (Bearman et al., 2015; Goldfried, 1984; Moran, 2011). The main motivation for trainees in psychotherapy is to become a practitioner rather than a researcher. Consequently, their feelings towards research are often anxious, negative and ambivalent. Clinical psychologists often recommend that less time be focused on research methods in training (Garfield \& Kurtz, 1976). Practitioners' and trainees' theoretical orientation - based on a particular epistemology - has an influence on the evaluation of research findings (Arthur, 2001; Cohen \& Suchy, 1979). From our point of view, to cope with all these challenges, it is not enough to simply increase the research methodology training, especially in psychotherapy training program, as suggested for example by Kernberg (2016); rather, a shared and deep reflection on epistemology of clinical and research activities by both faculty members and students is necessary. From such reflection, overcoming the gap between researchers and practitioners, science and practice will be more likely.

To investigate these ideas, we conducted an online survey with trainees in psychotherapy. Our central aim was to explore their tendencies to integrate research and clinical expertise, and to detect the explicit and implicit epistemology underlying their clinical and research practices. For this purpose, we selected three psychotherapy institutes that each had a different clinical orientation - cognitive-behavioral, relational-psychoanalytic and relational-systemic - and thus varied in their explicit epistemological values. In particular, we expected that:

- the majority of the trainees will be explicitly and implicitly more prone to a positivistic approach to research and clinical practice than to a complexity approach, because the mainstream psychological literature has not yet explicated the potential value of a shift toward a more complexity-oriented approach;

- the trainees of the relational institutes - psychoanalytic and systemic - will show greater propensity towards a complexity epistemology than the cognitive-behavioral trainees because the formal model of these two relational institutes in fact has introduced an epistemological shift that has not appeared in the cognitivebehavioral model; the two relational institutes have explicitly acknowledged and valued the influence of the therapist's subjectivity on all therapeutic processes, and no longer puts the emphasis on individuals but rather on relationships between individuals and on broader contexts of being, including the therapeutic one;

- some variables related to training and clinical goals will influence the trainees' epistemological orientation: a positivist epistemology is more likely to emerge in trainees who i) have produced an empirical master's thesis, ii) have attended a research oriented doctorate program or completed a course in research methodology during their psychotherapy training program, iii) have treated only a few patients during their training, and iv) were in the beginning of their psychotherapy training program;

- trainees with a positivistic epistemology underpinning their research and clinical practice will show a greater propensity for research activities (participation as researcher, and number of published research papers), higher perceived improvement of their patients (because they are more likely to rely on easily measured indications of therapeutic change), and larger perceived influence of theoretical and technical aspects on therapeutic outcome rather than interactive and subjective elements of therapeutic dyad.

\section{Methods}

\section{Participants}

Trainees from three Italian institutes with different psychotherapy training orientations were asked to respond to a survey on the importance of psychotherapy research in their current training. Of 357 trainees contacted by 
email or in person, 126 responded to the survey, yielding a response rate of 35 percent. Of those respondents, 102 identified as female (81\%) and 24 identified as male (19\%). The age of respondents ranged from 25 to 54 years $(M=31.05, S D=6.1)$.

Each institute focuses training on a specific orientation: cognitive-behavioral (from which 48 trainees responded, $38 \%$ of total), relational-psychoanalytic (from which 36 trainees responded, $29 \%$ of total), and relational-systemic (from which 42 trainees responded, 33\% of total). All three training programs require four years of training. Of the total 126 respondents, 31 trainees were in their first year of training (25\%), 30 in their second year (24\%), 28 in their third year $(22 \%)$, and 37 in their fourth year (29\%).

All respondents had previously achieved a master's degree in psychology, except one who had a master's degree in medicine; five were currently or had been doctoral students $(4 \%)$; most of them $(n=88,69.8 \%)$ had completed an empirical study as their master's degree thesis; only a few respondents $(n=22,17.5 \%)$ had attended a course in research methodology during their current training in psychotherapy; a third of respondents $(n=27$, $21.4 \%$ ) had conducted at least one empirical study since graduation; the average number of patients treated in the internship was $4.08(S D=4.21$; range $=0$ to 20$)$, and the average number of patients treated in private practice was $3.78(S D=8.44$; range $=0$ to 45$)$.

\section{Measures}

An ad hoc survey composed of 32 items was created to investigate four aspects of trainees' experiences.

\section{Education and biographical information}

Eight questions covering gender, age, year of attendance, psychotherapy training orientation, master's degree in psychology or in medicine, empirical or theoretical master's degree thesis, doctorate attendance, attendance of a research methodology course during psychotherapy training.

\section{Information on trainee's clinical and research practice}

Four questions about number of patients trainee has been treating in private and internship practice; percentage of patients who improved, were unchanged, dropped out of treatment; number of research papers published in an international scientific journal; whether they had participated in empirical studies as a researcher.

\section{Implicit epistemological assumptions detected from a clinical case interpretation}

The trainees were asked to read the clinical case of Peggy Isaac as described by Lawrence and Cabaniss (2014, pp. 119-120) and to answer the following four open-ended questions: If you had to make a diagnosis/case formulation to discuss the case, what would it be? On which elements of the case description would you mainly base this diagnosis/case formulation? What do you think were the etiopathogenetic elements that led to the development of the problem reported by the patient? What goals would you set if you started psychotherapy with this patient?

\section{Beliefs about psychotherapy research and propensities to integrate research and psychotherapy}

Fifteen questions, 14 of which were answered on a 7point Likert scale (Table 1) and one question requesting percentage estimates of the influence on the outcome of psychotherapy attributable to the patient's personality, the therapist's personality, theories and techniques, patienttherapist interaction, and life environment and events.

\section{Procedures}

All trainees from the three psychotherapy training institutes were contacted by researchers with an email soliciting participants for a 15-minute survey on the impact of scientific research on psychotherapy training. Participants could respond to the survey by accessing a website or by completing a hard copy of the survey during one of the planned days when one of the authors would be available in person at the institutes. The participants who gave their consent to participating in the survey were assured complete anonymity of their answers and of the training institutes in which they train.

Once a survey was completed, three of the authors categorized the responses given to the four open questions regarding the clinical vignette in order to identify the implicit epistemological assumptions of the trainees. In the first stage of this process, they discussed and reached an agreement on the distinctive elements of positivistic and complexity epistemology as summarized in the introduction section. This agreement guided the next stage in which they categorized each response as: i) mainly revealing a positivistic epistemology; ii) mainly revealing a complexity epistemology; or iii) revealing elements of both positivistic and complexity epistemologies. Each rater - independently and blind to the respondents institute - coded the responses to the four open questions of 70 participants. For the responses of 42 participants, the categorization was made by all three raters, and the interrater reliability was computed (Randolph, 2008; Warrens, 2010). According to the Fleiss's empirical rule (Fleiss, 1981), the three raters reached excellent agreement (overall: $\kappa=.77,95 \% \mathrm{CI}=.70$ to .83 ; first question: $\kappa=.92,95 \%$ $\mathrm{CI}=.84$ to 1.00 ; second question: $\kappa=.75,95 \% \mathrm{CI}=.61$ to .89 ; third question: $\kappa=.82,95 \% \mathrm{CI}=.71$ to .94 ; fourth question: $\kappa=.55,95 \% \mathrm{CI}=.39$ to .71$)$.

\section{Data analysis}

A principal components analysis was conducted to synthesize trainees' responses. The analysis identified fac- 
tors underlying the Likert-scale scores given to 13 items out of the 14 regarding beliefs about psychotherapy research and propensities to integrate research and psychotherapy. We examined solutions for two and three factors each and we preferred the two factors solution, which explained $64.1 \%$ of the variance, because: i) it met the criteria of the initial eigenvalues higher than unity (Kaiser, 1960); ii) the leveling off of eigenvalues on the scree plot were identifiable after two factors (Cattell, 1966); and iii) the third factor was composed of only one item. We then compared both varimax and oblimin rotations and decided to use the oblimin rotation because it showed an expected correlation between the two factors and because it provided the best-defined factor structure.

We retained only the items that contributed to a simple factor structure with primary factor loadings of .4 or above, and with no cross-loading of 3 or above (Osborne, 2014). Only the item How much the analysis of individual clinical cases can lead to scientifically based results? was eliminated because of a primary cross-loading over .3 .

For the final stage, a principal components factor analysis of the remaining 13 items was conducted, resulting in the two factors explaining $64.2 \%$ of the variance. All items in this analysis had primary loadings over .50 and cross-loadings below .24. The factor loading matrix for this final solution is presented in Table 1. Considering the item content of the two factors, the authors agreed upon names for the two factors: valuing objective measures and procedures and reliance on and trust of research. These factors explained $51.1 \%$ and $13.1 \%$ of the variance, respectively.
Composite scores were created for each of the two factors based on the mean of the items which had their primary loadings on each factor. Higher scores indicated greater presence of that dimension.

Finally, to test the presence of significant associations between implicit epistemological assumption (inferred by clinical vignette interpretation), explicit beliefs (synthetized by the two factors extracted), biographical information, and education and psychotherapy training variables, we conducted a series of one-way analyses of variance, Pearson's correlation tests, and chi-square statistics, depending on the measurement level of variables.

\section{Results}

\section{Trainees' implicit epistemological assumptions}

From responses given to the open questions about the Peggy Isaac clinical vignette (Lawrence \& Cabaniss, 2014), an inference can be made about psychotherapy trainees' implicit epistemological assumptions. Table 2 reports some examples of responses grounded in different epistemologies for each of the four questions.

The prevalent epistemology emerging from responses was the positivistic one (Figure 1). The first question asked for a diagnosis or a case formulation: two responses $(1.6 \%)$ were considered showing a mixed epistemology and two (1.6\%) a complexity epistemology; all the other trainees (96.8\%) gave a descriptive diagnosis, mainly using DSM categories. The second

Table 1. Factor loadings of principal components extracted with oblimin rotation from trainees' scores to 13 items on beliefs about psychotherapy research and clinical practice $(\mathrm{N}=126)$.

\begin{tabular}{|c|c|c|}
\hline Items & $\begin{array}{l}\text { Valuing objective measures } \\
\text { and procedures }\end{array}$ & $\begin{array}{l}\text { Reliance on and trust } \\
\text { in research }\end{array}$ \\
\hline Importance of measurements to assess one's clinical effectiveness & .94 & - \\
\hline Attempt to follow manualized and scientifically supported guidelines & .89 & - \\
\hline Incremental clinical effectiveness of manualized guidelines & .88 & - \\
\hline Need for external tools and evaluators for reliable measurements & .84 & - \\
\hline Measurability of what happens in psychotherapy & .81 & - \\
\hline Importance of initial diagnosis to plan treatment & .78 & - \\
\hline Need for RCT to obtain scientifically based results & .77 & - \\
\hline Ability to use measures to assess one's effectiveness & .76 & - \\
\hline Existence of specific techniques for specific patients & .72 & - \\
\hline Clinical work guided by specific goals and hypotheses about patients & .54 & - \\
\hline Usefulness of reading empirical literature for clinical improvement & - & .83 \\
\hline Ability to conduct an empirical study on one's practice & - & .79 \\
\hline Usefulness of research methodology courses for clinical training & .24 & .73 \\
\hline
\end{tabular}

Factor loadings $<.2$ are suppressed. A fourteenth item (How much the analysis of individual clinical cases can lead to scientifically based results?) was eliminated because of a primary crossloading over .3 (.33). RCT, randomized controlled trial. 
question was about the vignette elements used as the basis for a diagnosis or a case formulation: 21 responses (16.7\%) revealed a mixed epistemology; four responses $(3.2 \%)$ reflected a complexity epistemology, and the remaining responses $(80.2 \%)$ reflected a positivistic approach. To the third question (concerning the possible etiopathogenetic elements that led to the client's problems), one trainee $(0.8 \%)$ provided a response that was considered complex, seven responses $(5.6 \%)$ showed a mixed epistemology, while all the other trainees (93.6\%) gave a positivistic response. Responses to the last question (regarding the aims of treatment) were slightly more varied: 66 responses $(52.4 \%)$ showed a positivistic epistemology, 35 revealed mixed elements (27.8\%), and 25 were based on a complexity epistemology $(19.8 \%)$.

If we consider the responses to the four open questions regarding the clinical vignette as a whole, we can identify three groups with different levels of epistemological complexity: i) a positivistic group composed of $49.2 \%(n=62)$ of trainees whose responses indicated an exclusive positivistic epistemology; ii) a mixed-epistemology group consisting of $27.0 \% \quad(n=34)$ of trainees who provided responses showing both a positivistic epistemology and a mixed epistemology; and iii) a complexity prone group composed of $23.8 \%(n=30)$ of trainees who gave at least one response grounded in a complexity epistemology with others responses belonging to a positivistic or mixed epistemology. No trainee gave two, three or four responses based on a complexity epistemology.
Trainees' explicit beliefs about psychotherapy research and clinical practice

Factor analysis revealed two factors synthesizing trainees' explicit beliefs about psychotherapy research and clinical practice (Table 1).

The first factor that we have labeled valuing objective measures and procedures was composed of five items addressing clinical practice and five items addressing quantitative and objective measurements in psychotherapy. Trainees who obtained high scores in this factor believe psychotherapeutic processes are measurable; consider controlled and replicable research procedures reliable; trust quantitative and external measures to verify the effectiveness of treatments; seek clear objectives and hypotheses in matching specific diagnoses with specific therapeutic techniques; and follow manualized procedures in order to ensure greater effectiveness of interventions.

The second factor consisted of three items and was labeled reliance on and trust of research. High scores on this factor indicate that trainees rely on empirical data from psychotherapy research to inform and improve therapeutic efficacy and suggest confidence in their competence to conduct research in their own clinical practice.

The participants' average score on both factors was slightly over the mid-point on the 7-point scale $\left(1^{\text {st }}\right.$ factor: $M=3.21, S D=1.15, S E=0.10$, range $=0.30-5.50 ; 2^{\text {nd }}$ factor: $M=3.17, S D=1.12, S E=.10$, range=0.67-5.67). The two factors showed a moderate significant positive correlation with each other $(r=.288, \mathrm{P}<.001)$. The item How much the analy-

\section{Epistemology \\ 圆positivist田 mixed complexity}

96.8

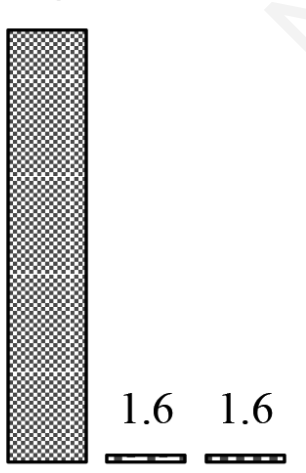

diagnosis or

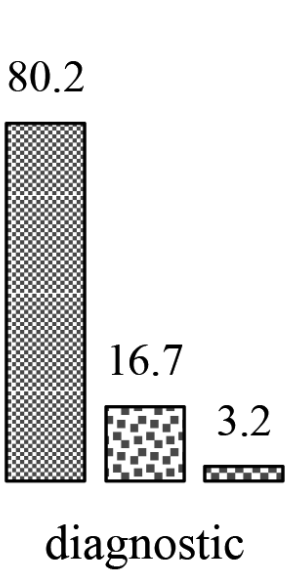

elements
93.7



etiopathogenetic

explanations



treatment

aims

Figure 1. Percentages of trainees' responses to the four open questions on clinical vignette grounded in a positivistic, mixed or complexity epistemology. 
sis of individual clinical cases can lead to scientifically based results? was omitted because it was the only item loading on a potential third factor; however, it had a high primary loading (.62) and a relatively low maximum primary cross-loading (.33) and to some extent it could be considered as an additional dimension $(M=3.17, S D=1.11$, $S E=0.10$, range $=1-6)$ positively correlated to the first $(r=.234, \mathrm{P}<.01)$ and second factor $(r=.208, \mathrm{P}<.05)$ extracted.

There was a relative convergence between trainees' explicit beliefs and implicit epistemological assumptions: The first factor (valuing objective measures and procedures) scores showed significant differences among the groups of trainees who had shown different implicit epistemological assumptions, $F(2.123)=17.33 ; \mathrm{P}<.001$ (Table 3). A post hoc analysis using Tukey's Honestly Significant Difference test (HSD; Tukey, 1949) indicated that the first factor average score was significantly greater $(\mathrm{P}<.001)$ in the group with implicit positivistic assumptions $(M=3.76$, $S D=0.99)$ than in the mixed epistemology $(M=2.64$, $S D=1.06)$ or in in the complexity prone group $(M=2.73$, $S D=1.06)$.
Regarding the perception of their clinical efficacy, trainees estimated that $54.02 \%(S D=21.75)$ of their patients were improved, $31.24 \%(S D=21.37)$ were unchanged, $5.41 \%(S D=7.73)$ were harmed, and $9.32 \%$ $(S D=10.11)$ dropped out of treatment.

The last question asked participants to indicate the relative influence that identified variables contributed to therapy outcome (indicated as a percentage with the sum of the contributions equaling $100 \%$ ). The results showed average percentages of $17.5 \%$ for patient's personality, $14.4 \%$ for therapist's personality, $18.6 \%$ for therapist's theories and techniques, $30.8 \%$ for patient-therapist interaction, and $18.7 \%$ for life environment and events. Considering the therapist's theories and techniques and the patient's personality together, as the variables more inline with a linear, unilateral and deterministic approach to psychotherapy - typical of a positivistic epistemology the combined perceived influence was $36.1 \%$, while the variables reflecting subjectivity and variability (patienttherapist interaction, therapist's personality, life environment and events) reached $63.9 \%$ of perceived influence.

Table 2. Examples of trainees' responses to the four clinical vignette questions reflecting opposite epistemologies.

\begin{tabular}{lll}
\hline Clinical vignette questions & Positivistic epistemology & Complexity epistemology \\
\hline Diagnosis or case formulation & $\begin{array}{l}\text { Generalized anxiety disorder, with agoraphobia } \\
\text { and separation anxiety with insecure attachment. }\end{array}$ & $\begin{array}{l}\text { I would need more information and above all face to face } \\
\text { meetings with the patient. }\end{array}$ \\
\hline Diagnostic elements & $\begin{array}{l}\text { Reoccurring symptoms; withdrawal at home } \\
\text { and relationship with mother and boyfriends. }\end{array}$ & $\begin{array}{l}\text { In patient's narrative the difficulty of being alone seems } \\
\text { to be an underlying theme. }\end{array}$ \\
\hline Etiology & $\begin{array}{l}\text { Neurotic temperament trait; embroiled and } \\
\text { distanced mother's attachment style; parents' } \\
\text { separation; abandonment by her partner. }\end{array}$ & $\begin{array}{l}\text { Patient' role in family dynamics and the consequent } \\
\text { choice of partner. }\end{array}$ \\
\hline Treatment goals & $\begin{array}{l}\text { To resume grocery shopping; to stop seeking } \\
\text { reassurance from mother and colleagues; } \\
\text { to improve concentration by managing arousal. }\end{array}$ & $\begin{array}{l}\text { To collaboratively understand the meaning of anxiety in } \\
\text { the present moment of the patient's life and with respect } \\
\text { to her family ties; to become aware of her current needs } \\
\text { and how to satisfy them. }\end{array}$ \\
\hline
\end{tabular}

Table 3. Statistically significant differences in trainee's explicit beliefs $(N=126)$.

\begin{tabular}{|c|c|c|c|c|c|}
\hline Trainees groups & Explicit beliefs & $\boldsymbol{F}$ & $d f$ & $\mathbf{P}$ & ES \\
\hline $\begin{array}{l}\text { Implicit epistemology } \\
\text { (positivistic } n=62 ; \text { mixed } n=34 \text {; } \\
\text { complexity } n=30 \text { ) }\end{array}$ & $\begin{array}{l}1^{\text {st }} \text { factor } \\
\text { Influence on outcome } \\
\text { Theories and techniques } \\
\text { Life environment and events }\end{array}$ & $\begin{array}{l}17.33 \\
6.45 \\
9.05\end{array}$ & $\begin{array}{l}2,123 \\
2,123 \\
2,123\end{array}$ & $\begin{array}{l}<.001 \\
\\
.002 \\
<.001\end{array}$ & $\begin{array}{l}.095 \\
.128\end{array}$ \\
\hline $\begin{array}{l}\text { Training orientation } \\
\text { (cognitive-behavioral } n=48 ; \\
\text { relational-psychoanalytic } n=36 \text {; } \\
\text { relational-systemic } n=42 \text { ) }\end{array}$ & $\begin{array}{l}1^{\text {st }} \text { factor } \\
\text { Influence on outcome } \\
\text { Therapist } \\
\text { Theories and techniques } \\
\text { Interaction }\end{array}$ & $\begin{array}{c}60.21 \\
\\
7.23 \\
11.56 \\
4.37 \\
\end{array}$ & $\begin{array}{l}2,123 \\
\\
2,123 \\
2,123 \\
2,123\end{array}$ & $\begin{array}{c}<.001 \\
\\
.001 \\
<.001 \\
.015\end{array}$ & $\begin{array}{l}.495 \\
.105 \\
.158 \\
.066\end{array}$ \\
\hline $\begin{array}{l}\text { Master's degree thesis } \\
\text { (empirical } n=88 ; \text { theoretical } n=38 \text { ) }\end{array}$ & $\begin{array}{l}1^{\text {st }} \text { factor } \\
\text { Influence on outcome } \\
\text { Therapist } \\
\text { Interaction }\end{array}$ & $\begin{array}{l}4.92 \\
11.77 \\
10.35\end{array}$ & $\begin{array}{l}1,124 \\
1,124 \\
1,124\end{array}$ & $\begin{array}{l}.001 \\
.002\end{array}$ & $\begin{array}{l}.038 \\
.087 \\
.077\end{array}$ \\
\hline Participation in empirical studies & $2^{\text {nd }}$ factor & 10.57 & 1,124 & .001 & .079 \\
\hline
\end{tabular}

ES, Effect Size $\left(\right.$ partial $\left.\eta^{2}\right)$. 


\section{Epistemology and training orientation}

The occurrences distribution analysis demonstrated a significant association between implicit epistemological assumptions and training orientation (i.e., cognitive-behavioral, relational-psychoanalytic, and relational-systemic), $\chi^{2}(4, N=126)=42.840, \mathrm{P}<.001$ (Table 4).

Cognitive-behavioral trainees were more likely to adopt a positivistic epistemology and less likely to endorse mixed epistemological assumptions and even less a complexity epistemology, while trainees who claimed a relational-psychoanalytic approach were less likely to base their interpretations on a positivistic conception and more likely to endorse a complexity epistemology. Furthermore, trainees who embraced a relational-systemic approach were less likely to assume a positivistic perspective and more likely a mixed epistemology.

Furthermore, the training orientation also affects the trainees' explicit beliefs. An analysis of variance computed in the two extracted factors showed statistically significant differences in trainees' explicit beliefs (Table 3) as a function of the training orientation, $F(2.123)=60.21$; $\mathrm{P}<.001$. Specifically, Tukey's HSD post hoc test showed that the average score of the first factor (valuing objective measures and procedures) significantly and progressively increased $(\mathrm{P}<.05)$ from the relational-systemic $(M=2.39$, $S D=0.96)$ to the relational-psychoanalytic $(M=2.83$, $S D=0.90)$ to the cognitive-behavioral group $(M=4.22$, $S D=0.62)$. No significant differences were found indeed in the second extracted factor among the trainee groups with a differently oriented training.

\section{Epistemology and research/clinical expertise}

The type of master's thesis completed (empirical vs theoretical) was statistically associated with the implicit epistemological assumptions, $\chi^{2}(2, N=126)=15.905$, $\mathrm{P}<.001$ (Table 4). Trainees who conducted an empirical study were more likely to adopt a positivistic conception and less likely to assume a complexity epistemology. Conversely, trainees who had conducted a theoretical thesis were more likely to endorse a complexity perspective and less likely a positivistic epistemology.

Also, the trainees' explicit beliefs significantly varied depending on the type of master's degree thesis carried out $(F(1.124)=4.99, \mathrm{P}<.05)$ (Table 3$)$ : Trainees who conducted an empirical study for the master's thesis scored higher on the valuing objective measures and procedures factor $(M=3.36, S D=1.18)$ than trainees who conducted a theoretical thesis $(M=2.87, S D=1.04)$.

No associations were found between implicit epistemological assumptions and number of patients in care, year of training, completion of a research methodology course during psychotherapy training, or doctoral level training program. These variables also did not significantly influence the scores on the factors of trainees' explicit beliefs.

\section{Epistemology and attitude toward research/clinical practice}

Among the three groups defined by different implicit epistemological assumptions (positivistic, mixed, and complexity prone groups) there were significant differ-

Table 4. Distribution of implicit epistemological assumptions within training orientation and thesis type.

\begin{tabular}{|c|c|c|c|c|}
\hline & Implicit epistemological assumptions & $\begin{array}{c}\text { Positivistic } \\
n=62\end{array}$ & $\begin{array}{c}\text { Mixed } \\
n=34\end{array}$ & $\begin{array}{c}\text { Complexity } \\
n=\mathbf{3 0}\end{array}$ \\
\hline \multicolumn{5}{|l|}{ Training orientation } \\
\hline \multirow[t]{3}{*}{ Cognitive-behavioral $n=48$} & Count (expected) & $41(23.6)$ & $6(13.0)$ & $1(11.4)$ \\
\hline & $\%$ within orientation & 85.4 & 12.5 & 2.1 \\
\hline & Adjusted residuals & 6.4 & -2.9 & -4.5 \\
\hline \multirow[t]{3}{*}{ Relational- psychoanalytic $n=36$} & Count (expected) & $9(17.7)$ & $12(9.7)$ & $15(8.6)$ \\
\hline & $\%$ within orientation & 25.0 & 33.3 & 41.7 \\
\hline & Adjusted residuals & -3.4 & 1.0 & 3.0 \\
\hline \multirow[t]{3}{*}{ Relational-systemic $n=42$} & Count (expected) & $12(20.7)$ & $16(11.3)$ & $14(10.0)$ \\
\hline & $\%$ within orientation & 28.6 & 38.1 & 33.3 \\
\hline & Adjusted residuals & -3.3 & 2.0 & 1.8 \\
\hline \multicolumn{5}{|l|}{ Master's degree thesis category } \\
\hline \multirow[t]{3}{*}{ Empirical $n=88$} & Count (expected) & $53(43.3)$ & $21(23.7)$ & $14(21.0)$ \\
\hline & $\%$ within thesis type & 60.2 & 23.9 & 15.9 \\
\hline & Adjusted residuals & 3.8 & -1.2 & -3.2 \\
\hline \multirow[t]{3}{*}{ Theoretical $n=38$} & Count (expected) & $9(18.7)$ & $13(10.3)$ & $16(9.0)$ \\
\hline & $\%$ within thesis type & 23.7 & 34.2 & 42.1 \\
\hline & Adjusted residuals & -3.8 & 1.2 & 3.2 \\
\hline
\end{tabular}

In italics: statistically significant adjusted standardized residuals $(>1.96)$ 
ences in the influence on outcome attributed to theories and techniques $(F(2.123)=6.45, \mathrm{P}<.01)$ and to life environment and events $(F(2.123)=9.05, \mathrm{P}<.001)$ (Table 3$)$. Post hoc analyses using the Tukey's HSD test for significance indicated that i) the influence of theories and techniques on outcome was significantly greater $(\mathrm{P}<.05)$ in the group with implicit positivistic assumptions $(M=21.61, S D=11.04)$ than in the mixed epistemology $(M=16.48, S D=7.05)$ or complexity prone groups ( $M=14.99, S D=7.09)$; ii) the influence of life environment and events on outcome was significantly greater $(\mathrm{P}<.001)$ in the complexity prone group $(M=25.45, S D=13.42)$ than in the mixed epistemology $(M=15.62, S D=9.12)$ or the positivistic groups $(M=17.06, S D=9.24)$.

As well the three groups of psychotherapy training orientations significantly varied on the influence on outcome attributed to therapist's personality $(F(2.123)=7.23$, $\mathrm{P}<.001)$ to theories and techniques $(F(2.123)=11.56$, $\mathrm{P}<.001)$ and to patient-therapist interaction ( $F$ $(2.123)=4.37, \mathrm{P}<.05)$ (Table 3). Specifically, Tukey's HSD post hoc test showed that: i) the perceived influence of therapist's personality on outcome was significantly lower $(\mathrm{P}<.05)$ among cognitive-behavioral trainees $(M=11.86, S D=5.42)$ than in the relational-systemic $(M=15.05, S D=6.50)$ and relational-psychodynamic groups ( $M=17.05, S D=7.24)$; ii) the influence of theories and techniques on outcome was significantly greater $(\mathrm{P}<.01)$ in cognitive-behavioral trainees $(M=23.40$, $S D=11.54)$ than in the relational-systemic $(M=14.71$, $S D=15.17)$ and in the relational-psychodynamic groups $(M=16.91 ; S D=8.35)$; iii) the influence of patient-therapist interaction on outcome was significantly greater $(\mathrm{P}<.05)$ in relational-systemic trainees $(M=35.46$, $S D=15.45)$ than in the relational-psychodynamic $(M=27.38, S D=12.32)$ or in the cognitivist-behavioral groups $(M=29.20, S D=10.72)$.

Considering the type of master's degree thesis, there were significant differences in the perceived influence on psychotherapy outcome attributed to patient-therapist interaction $(F(1.124)=10.35, \mathrm{P}<.01)$ and to therapist's personality, $F(1.124)=11.77 ; \mathrm{P}<.001$. Trainees who conducted an empirical thesis reported a greater influence of patienttherapist interaction on outcome $(M=33.18, S D=12.77)$ and a smaller influence of therapist's personality on outcome ( $M=13.13, S D=6.41)$ compared to trainees who conducted a theoretical thesis $(M=25.19, S D=12.82$; and $M=17.37$, $S D=6.32$, respectively).

Finally, the correlations analysis showed that the greater the first factor score (valuing objective measures and procedures), the greater the percentage attributed to the therapist's theories and techniques $(r=.400, \mathrm{P}<.001)$ and the smaller the percentage related to the patient-therapist interaction $(r=-.251, \mathrm{P}<.01)$.

Regarding the relationship between epistemology and trainees' perception of their clinical efficacy, and between epistemology and trainees' participation in empirical stud- ies or research publications, the results were different depending on whether one considers the epistemological implicit assumptions or the explicit beliefs of the trainees.

No associations were found between implicit epistemological assumptions and percentages of improved/unchanged/harmed/dropped out patients, number of papers published in an international scientific journal or participation in research studies as a researcher. However, within explicit beliefs the reliance on and trust in research factor showed a significant positive correlation with the percentage of improved patients $(r=.294, \mathrm{P}<.01)$, a significant negative correlation with the percentage of patients unchanged by treatment $(r=-.406, \mathrm{P}<.001)$, and a significant positive correlation with the percentage of patient drop outs $(r=.239, \mathrm{P}<.01)$. The number of papers published in an international scientific journal was positively correlated with the need for objective measures and procedures factor $(r=.210, \mathrm{P}<.05)$. The research propensity and trust factor was also significantly associated with participation in an empirical study as researcher $(F(1,123)=10.57$, $\mathrm{P}<.001)$ (Table 3). Trainees who conducted at least one empirical study had higher scores on the second factor, reliance on and trust in research $(M=3.76, S D=1.33)$ than those who had not conducted any $(M=3.00, S D=1.00)$.

\section{Discussion}

The analysis of implicit epistemological assumptions showed that the clinical reasoning of psychotherapy trainees is still mainly based on a positivistic epistemology. Only in a few cases did respondents add some elements reflecting a complexity epistemology to the primarily positivist explanations, and none of the respondents provided all complexity-oriented responses. We consider this result consistent with the hypothesis that in current psychotherapy training there is little room for clear and explicit epistemological reflection that would open the possibility for an epistemological approach better suited to the characteristics of psychotherapeutic intervention. In the absence of such reflection, by default the most widespread epistemology in western culture is adopted. Positivistic reasoning is the primary guide in making diagnoses and giving etiological explanations, although this is mitigated when the trainees wonder about the objectives of their psychotherapeutic interventions. This is perhaps due to the fact that diagnosis is easier to conceptualize and control cognitively than is planning and managing a therapeutic relationship in which change happens.

The study revealed that positivistic epistemology also emerges at the explicit level. The factor analysis that resulted in two dimensions - valuing objective measures and procedures and reliance on and trust in research - registered average scores slightly higher than the neutral value, suggesting trainees on average rely on quantitative research data and give positive value to objective procedures and measurements in both research and clinical fields. In addi- 
tion, the higher the scores in these dimensions the greater the perceived influence of the therapist's theories and techniques on treatment outcome and the smaller the perceived influence of patient-therapist interaction.

Both implicit assumptions and explicit beliefs supported the hypothesis that different clinical orientations would show some differences in epistemology. Trainees at the cognitive-behavioral institute were inclined to use a positivistic epistemology, whereas trainees from the two institutes that are relationship-oriented (i.e., the systemic institute and the psychoanalytic institute) showed at least some propensity for a complexity epistemology. Although our study can be considered a pilot study and our results are considered preliminary, this tendency supported our hypothesis in that cognitive-behavioral approaches are based on rationalism and empiricism, both on the theoretical and the methodological levels, while relationship-oriented approaches recognize greater complexity. These differences among orientations also appeared in the attributions of influences of several variables. Trainees in the cognitive-behavioral approach gave a greater importance to adherence to theories and techniques as the factor that determines therapeutic outcome, while the relational-systemic and the relational-psychodynamic approaches gave more importance to factors such as the therapist's personality and the patienttherapist interaction in therapeutic outcome.

Beyond these differences between cognitive-behavioral trainees and students from the two relational institutes mentioned above, it is precisely the relational approaches that showed the greatest incongruity between the explicit theoretical orientation of their own institute and the implicit and explicit epistemological assumptions emerging from their responses. As expected, the influence of the dominant positivistic epistemology in western culture is very strong even for those who try to break away from it.

It is noteworthy that, contrary to what we expected, the implicit epistemological assumptions do not affect scientific productivity (i.e., number of publications, participation in research projects) or clinical productivity (i.e., number of patients, perception of clinical efficacy), nor do they affect reliance on research and confidence in one's research capabilities. Therefore, adopting a positivistic epistemology does not guarantee application of research practices and reliance on literature data, suggesting that the complexity needed to understand the clinical phenomena does not allow adoption of a completely positivistic epistemology in clinical practice.

Having already attended a methodology course during the psychotherapy training program or having attended a doctorate program were not associated with an implicit positivistic epistemology nor with scientific productivity. Neither does the training year influence the trainees' epistemological assumptions. These data together support the hypothesis that the gap between practice and research might be narrowed more by reflection on the epistemological approach than by knowledge of empirical research methods, as suggested for example by Kernberg (2016). In fact, in our opinion it is not the lack of knowledge of research methods but rather the lack of reflection on the epistemology they reflect that constrains attitudes toward both clinical and research practice.

Another interesting result concerns the kind of master's thesis students have completed. Having conducted an empirical study for the thesis rather than a theoretical study is associated with a positivistic epistemology. Since the topic and type of thesis are generally decided jointly by student and supervisor, this choice could reflect a personal epistemological propensity of the student. Even when the student-supervisor match was forced, we think it would influence the future student's epistemological position. This suggests that epistemological values may be grounded in the early personal history, and together with personality features might influence the clinical orientation chosen for one's psychotherapy training (Arthur, 2000).

Overall, the results seem to elucidate an aspect of psychotherapy training that is often ignored: the relationship between the epistemology embraced by a psychotherapist in training, and their subsequent research and clinical practice. The research on psychotherapy training is mainly focused on understanding which personal features of the learner or technical features of the psychotherapy courses are most important to insure the best professional pathway. Among these are: trainee's personal therapy (Murphy, 2005), supervision by expert trainers (Goodyear \& Guzzardo, 2000), and training structure (Henry, Schacht, Strupp, Butler, \& Binder, 1993). These findings suggest that a deeper awareness of one's own epistemological assumptions could also help trainees develop a more theory-coherent and research-informed clinical practice. In fact, we agree with Fourie's (1996) hypothesis that the researchpractice gap endures and indeed increases as long as positivistic epistemology remains predominant in training. Shifting towards a complexity epistemology might give trainees more consistency between what they feel when they face the complexity of clinical activity and the available theoretical tools they have to apply to their work. Furthermore, such a shift could expand development of possibilities for using research findings and procedures in one's own clinical practice beyond those considered scientific in a positivistic framework. If this shift had already been made by all trainees involved in this study, we might have engaged more respondents in the survey than we did. Precisely because of the epistemology adopted by today's trainees, many of them may have perceived our survey as a representative example of a reductionist, useless research practice far from their clinical work.

Of course, this study has important limitations, which require considering these results as preliminary and in need of further and more robust confirmation. First of all, the survey we constructed and used should be further tested both in the psychometric aspects and in the reliability of qualitative coding of open-ended answers. Additionally, the 
response rate of about $35 \%$ of those solicited for participation in the study is not high and might introduce participation bias. However, this response rate seems in line with studies in which researchers are not part of the participants' institutions and in which remote solicitation of potential respondents is made. Since there was no reward for participation, perhaps it was just the proclivity towards research that differentiated a respondent from a non-respondent. We have no data to suggest any other substantial differences between respondents and non-respondents.

Another limitation regards the small number of training institutes involved and the fact they are all located in Italy. From a positivistic point of view these elements represent a constraint to the generalizability of the results, but from a complexity perspective they represent a richer guarantee of contextual and local knowledge of a specific phenomenon that can be similar or different from what happens in other contexts. And, as we said, one perspective does not exclude the other. Comparing the results of this study with similar studies from other institutes and countries, and with different clinical orientations would reveal specificities and generalities that allow deeper understanding of the central role of epistemology in clinical practice, in research activity, and in psychotherapy training.

We are aware that epistemological change requires great effort because it involves changing deeply rooted, automatic and implicit ways of thinking. However, we think that the results obtained in this study begin to suggest potential value in developing a complexity point of view to counterbalance the positivistic paradigm with the goal of making psychotherapy more congruent with the complex nature of the endeavor and consequently more useful for its users than the dominant positivistic approach to research and practice.

\section{Conclusions}

The results of this study highlight the central role that epistemology plays in maintaining or reducing the practiceresearch divide in psychotherapy. Many trainees in psychotherapy show a positivistic epistemology underlying their way of thinking about clinical practice and research activity. Even trainees adopting relational approaches have difficulty making a shift towards a constructionist epistemology, which is more consistent with the complexity of clinical phenomena. These findings suggest that to overcome the research-practice gap and to help trainees foster a more theory-coherent and research-informed clinical practice, it would be useful to promote a deeper reflection on one's own epistemological assumptions.

\section{References}

Ackerman, S. L., Darling, K. W., Lee, S. S. J., Hiatt, R. A., \& Shim, J. K. (2016). Accounting for complexity: Gene-envi- ronment interaction research and the moral economy of quantification. Science, Technology \& Human Values, 41, 194-218. doi: $10.1177 \% 2$ F0162243915595462

APA Presidential Task Force on Evidence-Based Practice. (2006). Evidence-based practice in psychology. American Psychologist, 61, 271-285. doi: 10.1037/0003-066X.61. 4.271

Arthur, A. R. (2000). The personality and cognitive-epistemological traits of cognitive-behavioral and psychoanalytic psychotherapists. British Journal of Medical Psychology, 73, 241-255. doi: 10.1348/000711200160453

Arthur, A. R. (2001). Personality, epistemology and psychotherapists' choice of theoretical model: A review and analysis. European Journal of Psychotherapy, Counselling \& Health, 4, 45-64. doi: 10.1080/13642530110040082

Assoun, P. L. (1981). Introduction à l'épistémologie freudienne [Introduction to the freudian epistemology]. Paris, France: Payot.

Barlow, D. H. (1981). On the relation of clinical research to clinical practice: Current issues, new directions. Journal of Consulting and Clinical Psychology, 49, 147-155. doi: 10.1037/0022-006X.49.2.147

Bateson, G. (1972). Steps to an ecology of mind. New York, NY: Ballantine Books.

Bateson, G. (1979). Mind and nature: A necessary unity. New York, NY: Dutton.

Bearman, S. K., Wadkins, M., Bailin, A., \& Doctoroff, G. (2015). Pre-practicum training in professional psychology to close the research-practice gap: Changing attitudes toward evidence-based practice. Training and Education in Professional Psychology, 9(1), 13-20. doi: 10.1037/tep0000052.

Bertin, G. (2013). Sensemaking and social research in the analysis of educational processes: some methodological problems. Italian Journal of Sociology of Education, 5, 147-173. doi: 10.14658/pupj-ijse-2013-3-9

Beutler, L. E., Williams, R. E., Wakefield, P. J., \& Entwistle, S. R. (1995). Bridging scientist and practitioner perspectives in clinical psychology. American Psychologist, 50, 984-994. doi: 10.1037/0003-066X.50.12.984

Boisvert, C. M., \& Faust, D. (2006). Practicing psychologists' knowledge of general psychotherapy research findings: implications for science-practice relations. Professional Psychology: Research and Practice, 37, 708-716. doi: 10.1037/0735-7028.37.6.708

Butz, M. (1997). Chaos and complexity: implications for psychological theory and practice. Washington, DC: Taylor \& Francis.

Cambel, A. B. (1993). Applied chaos theory. A paradigm for complexity. New York, NY: Academic Press.

Capra, F. (1983). The turning point: science. Society and the rising culture. London, UK: Flamgo.

Casti, J. L. (1989). Paradigms lost. Images of man in the mirror of science. London, UK: Scribners.

Castonguay, L. G., \& Muran, J. C. (2015). Fostering collaboration between researchers and clinicians through building practice-oriented research: An introduction. Psychotherapy Research, 25, 1-5. doi: 10.1080/10503307.2014.966348

Cattell, R. B. (1966). The scree test for the number of factors. Multivariate Behavioral Research, 1, 245-276. doi: 10.1207/s15327906mbr0102_10

Ceruti, M. (1996). Constraints and possibilities. New York, NY: Gordon and Breach.

Ceruti, M. (2015). La fine dell'onniscenza: Epistemologie della 
complessità [The end of omniscence: Epistemologies of the complexity]. Rome, Italy: Studium.

Ceruti, M. (2018). Il tempo della complessità [The time of complexity]. Milano: Cortina.

Cohen, L. H., \& Suchy, K. R. (1979). The bias in psychotherapy research evaluation. Journal of Clinical Psychology, 35, 184-187. doi: 10.1002/1097-4679

Cohen, L. H., Sargent, M. M., \& Sechrest, L. B. (1986). Use of psychotherapy research by professional psychologists. American Psychologist, 41, 198-206. doi: 10.1037/0003066X.41.2.198

Cronbach, L. J. (1975). Beyond the two disciplines of scientific psychology. American Psychologist, 30, 116-127. doi: $10.1037 / \mathrm{h} 0076829$

Crooke, P. J., \& Olswang, L. B. (2015). Practice-based research: Another pathway for closing the research-practice gap. Journal of Speech, Language, and Hearing Research, 58, 1871-1882. doi: 10.1044/2015_JSLHR-L-150243

Darlaston-Jones, D. (2007). Making connections: the relationship between epistemology and research methods. The Australian Community Psychologist, 19(1), 19-27.

De Robertis, D. (2001). Notes for a definition of the concept of psychoanalytical epistemology. International Forum of Psychoanalysis, 10, 133-143. doi: 10.1080/080370601300177 205

Dimitrov, V., \& Woog, R. (2000). Making sense of social complexity through strange attractors. Paper presented at the 1st International Conference on Systems Thinking in Management, Geelong, Australia. Retrieved from: http://ftp.informatik.rwth-aachen.de/Publications/CEUR-WS/Vol-72/023 \%20Dimitrov\%20Sense.pdf

Drapeau, M., \& Hunsley, J. (2014). Where's the science? Introduction to a special issue of Canadian psychology on science in psychology. Canadian Psychology, 55, 145-152. doi: $10.1037 / \mathrm{a} 0037321$

Engel, G. L. (1992). How much longer must medicine's science be bound by a seventeenth century world view? Psychotherapy and Psychosomatics, 57, 3-16. doi: 10.1159/000288568

Fitzpatrick, M. (2012). Blurring practice-research boundaries using progress monitoring: A personal introduction to this issue of Canadian Psychology. Canadian Psychology, 53, 75-81. doi: 10.1037/a0028051

Fleiss, J. L. (1981). Statistical methods for rates and proportions. Hoboken, JN: Wiley.

Ford, D. H., \& Urban, H. B. (1998). Contemporary models of psychotherapy: a comparative analysis (2nd ed.). New York, NY: Wiley.

Fourie, D. P. (1996). The research/practice gap in psychotherapy: From discovering reality to making sense. Journal of Contemporary Psychotherapy, 26, 7-22. doi: 10.1007/ BF02307702

Gallo, K. P., \& Barlow, D. H. (2012). Factors involved in clinician adoption and nonadoption of evidence-based interventions in mental health. Clinical Psychology: Science and Practice, 19, 93-106. doi: 10.1111/j.1468-2850.2012.01276.x

Garfield, S. L., \& Kurtz, R. (1976). Clinical psychologists in the 1970s. American Psychologist, 31, 1-9. doi: 10.1037/0003066X.31.1.1

Gergen K. (1982). Toward transformation in social knowledge. New York, NY: Springer Verlag.

Goldfried, M. R. (1984). Training the clinician as scientist-professional. Professional Psychology: Research and Practice, 15, 477. doi: 10.1037/0735-7028.15.4.477
Goodyear, R. K., \& Guzzardo, C. R. (2000). Psychotherapy supervision and training. In S. D. Brown \& R. W. Lent (Eds.), Handbook of counseling psychology (pp. 83-108). Hoboken, NJ: Wiley.

Guba, E. G. \& Lincoln, Y. S. (1988). Do inquiry paradigms imply inquiry methodologies? In D. M. Fetterman (Ed.), Qualitative approaches to evaluation in education. The silent scientific revolution. New York, NY: Praeger.

Hammersley, M. \& Atkinson, P. (1983). Ethnography: principles in practice. London, UK: Tavistock.

Hayes, S. C. (1981). Single case experimental design and empirical clinical practice. Journal of Consulting and Clinical Psychology, 49, 193-211. doi: 10.1037/0022-006X.49.2.193

Henry, W. P., Schacht, T. E., Strupp, H. H., Butler, S. F., \& Binder, J. L. (1993). Effects of training in time-limited dynamic psychotherapy: mediators of therapists' responses to training. Journal of Consulting and Clinical Psychology, 61, 44-447. doi: 10.1037/0022-006X.61.3.441

Hoffman, I. Z. (2009). Doublethinking our way to "scientific" legitimacy: the desiccation of human experience. Journal of the American Psychoanalytic Association, 57, 1043-1069. doi: $10.1177 / 0003065109343925$

Hoshmand, L. T., \& Polkinghorne, D. E. (1992). Redefining the science-practice relationship and professional training. American Psychologist, 47, 55-66. doi: 10.1037/0003066X.47.1.55

Kaiser, H. F. (1960). The application of electronic computers to factor analysis. Educational and Psychological Measurement, 20, 141-151. doi:10.1177/001316446002000116

Kazdin, A. E. (1981). Drawing valid inferences from case studies. Journal of Consulting and Clinical Psychology, 49, 183192. doi: 0022-006X/81/4902-0183500.75

Kazdin, A. E. (2016). Closing the research-practice gap: How, why, and whether. Clinical Psychology: Science and Practice, 23, 201-206. doi: 10.1111/cpsp.12155

Kenny, V. (1989). Life, the multiverse and everything. An introduction to the ideas of Humberto Maturana. In A. L. Goudsmit (Ed.). Self-organization in psychotherapy. Demarcations of a new perspective. Berlin, Germany: SpringerVerlag.

Kernberg, O. F. (2016). Psychoanalytic education at the crossroads: Reformation, change and the future of psychoanalytic training. London, UK: Routledge.

Kiesler, D. J. (1981). Empirical clinical psychology: myth or reality? Journal of Consulting and Clinical Psychology, 49, 212-215. doi: 0.1037/0022-006X.49.2.212

Kuhn, T. S. (1962). The structure of scientific revolutions. Chicago, IL: University of Chicago Press.

Lawrence, R. E., \& Cabaniss, D. L. (2014). Case 5.5. Always on edge. In Barnhill, J. W. (Ed.), DSM-5 clinical cases (pp. 119120). Washington, DC: American Psychiatric Association.

Liddle, H. A. (1991). Empirical values and the culture of family therapy. Journal of Marital and Family Therapy, 17, 327348. doi: 10.1111/j.1752-0606.1991.tb00903.x

Lilienfeld, S. O., Ritschel, L. A., Lynn, S. J., Cautin, R. L., \& Latzman, R. D. (2013). Why many clinical psychologists are resistant to evidence-based practice: Root causes and constructive remedies. Clinical Psychology Review, 33, 883 900. doi:10.1016/j.cpr.2012.09.008

Luhmann, N. (1995). Social systems. Stanford, CA: Stanford University Press.

Melidonis, G. (1989). Exploring an alternative option for clinical research. Australian and New Zealand Journal of Family 
Therapy, 10, 227-232. doi: 10.1002/j.1467-8438.1989. tb00772.x

Miller, J. H., \& Page, S. E. (2007). Complex adaptive systems. An introduction to computational models of social life. Princeton: Princeton University Press.

Moran, P. (2011). Bridging the gap between research and practice in counselling and psychotherapy training: Learning from trainees. Counselling and Psychotherapy Research, 11, 171-178. doi: 10.1080/14733145.2010.509510

Morrow-Bradley, C. \& Elliott, R. (1986). Utilization of psychotherapy research by practicing psychotherapists. American Psychologist, 41, 188-197. doi: 10.1037/0003066X.41.2.188

Murphy, D. (2005). A qualitative study into the experience of mandatory personal therapy during training. Counselling and Psychotherapy Research, 5, 27-32. doi: 10.1080/ 14733140512331343868

Osborne, J. W. (2014). Best practices in exploratory factor analysis. Seattle, WA: Create Space Publishing.

Randolph, J. J. (2008). Online kappa calculator [Computer software]. Retrieved from http://justus.randolph.name/kappa

Rosas, S. R. (2017). Group concept mapping methodology: toward an epistemology of group conceptualization, complexity, and emergence. Quality \& Quantity, 51, 1403-1416. doi: 10.1007/s11135-016-0340-3.

Ryan, A. B. (2006). Post-positivistic approaches to research. In M. Antonesa (Ed.), Researching and writing your thesis: a guide for postgraduate students (pp. 12-26). Maynooth, Ireland: MACE.

Schön, D. A. (2017). The reflective practitioner: how professionals think in action. London, UK: Routledge.

Tukey, J. (1949). Comparing individual means in the analysis of variance. Biometrics, 5, 99-114. doi: 10.2307/3001913

Tasca, G. A., Grenon, R., Fortin-Langelier, B., \& Chyurlia, L.
(2014). Addressing challenges and barriers to translating psychotherapy research into clinical practice: the development of a psychotherapy practice research network in Canada. Canadian Psychology/Psychologie Canadienne, 55, 197-203. doi: 10.1037/a0037277

Varela, F. (1989). Reflections on the circulation of concept between a biology of cognition and systemic family therapy. Family Process, 28, 15-24. doi: 10.1111/j.1545-5300. 1989.00015.x

Wall, J. M., Kwee, J. L., Hu, M., \& McDonald, M. J. (2017). Enhancing the hermeneutic single-case efficacy design: Bridging the research-practice gap. Psychotherapy Research, 27, 539-548. doi: 10.1080/10503307.2015.1136441

Warrens, M. J. (2010). Inequalities between multi-rater kappas. Advances in Data Analysis and Classification, 4, 271-286. doi:10.1007/s11634-010-0073-4

Watson, J. B. (1913). Psychology as the behaviorist views it. Psychological Review, 20, 158-177. doi: 10.1037/h0074428

Watzlawick, P., Bavelas, J. B., \& Jackson, D. D. (1971). Pragmatics of human communication: A study of interactional patterns, pathologies and paradoxes. New York, NY: Norton.

Westen, D. (2007). Discovering what works in the community: toward a genuine partnership of clinicians and researchers. In S. G. Hofmann \& J. Weinberger (Eds.), The art and science of psychotherapy (pp. 3-30). New York, NY: Routledge.

Wilson, J. L., Armoutliev, E., Yakunina, E., \& Werth Jr, J. L. (2009). Practicing psychologists' reflections on evidencebased practice in psychology. Professional Psychology: Research and Practice, 40, 403-409. doi: 10.1037/a0016247

Young, T. R. (1995). Chaos theory and social dynamics: foundations of postmodern social science. In R. Robertson \& A. Combs (Eds.), Chaos theory in psychology and the life Sciences (pp. 217-233). Mahwah, NJ: Erlbaum. 